\begin{tabular}{|c|c|c|}
\hline & $\begin{array}{c}\text { Gazi University } \\
\text { Journal of Science }\end{array}$ & 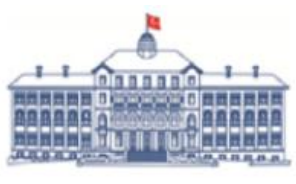 \\
\hline & http://dergipark.gov.tr/gujs & \\
\hline
\end{tabular}

\title{
An Electromagnetic Energy Harvester for Wireless Sensors from Power Lines: Modeling and Experiment Verification
}

\author{
Mahmut KABAKULAK*(D), Serdal ARSLAN \\ Department of Electrical Harran University Birecik Vocational High School, Sanliurfa, Turkey \\ Highlights \\ - This paper focuses on electromagnetic harvester system for data acquisition. \\ - The performances of electromagnetic harvesters have been studied via Ansys Maxwell software. \\ - Data were successfully obtained from the system which has been tested in laboratory environment.
}

\section{Article Info}

Received:04 July 2020

Accepted:09 Dec 2020

\section{Keywords \\ Energy harvester \\ Harvester \\ Ansys Maxwell \\ Monitoring \\ Power grid}

\begin{abstract}
In this study, harvesters, sensors and data acquisition cards were designed and tested to obtain data from transmission lines. In this context; numerical analyses of harvesters with two different core geometries were performed with Ansys Maxwell software. Then the voltage and power harvested by the harvesters at different line currents were measured with pre-tests in the laboratory. Analyses' results and pre-test's results were examined and it was determined that the geometric structure (double C) model suitable for use in overhead transmission lines with high current could be used. The field test was carried out on a distribution transformer. In the field test, the harvester mounted on the transformer supply line has charged the battery supplying the sensor circuit with sufficient power to ensure normal operation of the system. A circuit is designed to measure air temperature, humidity, pressure, altitude, air quality and transformer temperature and to transmit them to the remote distance with RF transmitter. Data received on the data collection card can be recorded at certain periods and time-based graphs of the data can be obtained by a computer interface program. The energy of this circuit is to meet the energy harvested from the electromagnetic field.
\end{abstract}

\section{INTRODUCTION}

With the advancement of semiconductor technology, a wide variety of sensors are now able to operate at very low power levels, such as milliwatts. Thus, the sensors are widely used in home applications, smart grid applications, monitoring of transmission-distribution lines, obtaining meteorological data and our daily life. It is important that the energy requirements of the sensors to be used for some specific applications are met internally or externally. For example; in order to operate the outdoor condition monitoring sensors, systems with electrical energy battery, solar or wind energy support are tried to be provided. Recently, the method of energy harvesting from the electromagnetic field around the line has been promising in terms of being unaffected by adverse environmental conditions and being an uninterrupted energy source for the sensors $[1,2]$.

The energy demands of large consumers and power plants entering and leaving the network cause large fluctuations in transmission lines. These fluctuations adversely affect the reliability and quality of the transmission line. With the network of sensor nodes to be installed in transmission lines, the current loads of transmission lines can be monitored online and measures can be taken to increase the reliability and energy quality of the line [3]. It can measure many energy parameters consumed using an energy analyzer [4]. Energy monitoring can be done with Arduino microcontroller and PLC [5,6]. In addition, energy parameters can be obtained with the IoT-based monitoring system [7]. In recent years, it has been possible to meet the energy of sensor systems with low levels of energy with solar and wind modules. However, the 
extreme sensitivity of these modules to the weather conditions, the battery life limitation, the need for maintenance of moving parts and the short service life have also been disadvantages [8].

The energy harvesting from the electromagnetic field in the transmission lines provides energy to the wireless power transmission systems and the monitoring equipment on the transmission masts $[9,10]$. This idea has been quite remarkable. In recent years, there have been designs and applications for obtaining data in home applications [11], charging unmanned aircraft [12], and lightning impulse measurement systems [13], and obtaining meteorological data in earth [14].

Considering the operating frequencies of electromagnetic energy harvesters, it enters non-radiative wireless inductive energy transfer types. The basis of inductive energy transmission, which is considered to be a two-part transformer, is the transfer of energy using the inductive coupling between the two circuits. In electromagnetic harvesters that generate energy through inductive energy transmission, the primary coil is formed by the line itself and the secondary coil is formed by a core-dependent or core-independent winding. Since very low energy can be obtained from these systems, it is called as energy harvester rather than wireless energy transmission in the literature.

The method of energy harvesting from the electromagnetic field is based on the current transformer logic. With this type of harvester, different data can be obtained with both the current of the line and the sensors to be added. It is possible to obtain a higher power from the harvester by adding a resonance capacitor to a harvester designed as a current transformer. It is known that the most important parameters in obtaining energy by electromagnetic induction are the magnetic permeability of the core material, the size and the number of windings. When the energy harvested by three different toroidal electromagnetic harvesters using ferrite, nanocrystalline and iron powder as core material wrapped with different sizes and different sipers on a conductor on which the line current is constant, $315.6 \mathrm{~mW}$ nanocrystalline, core powder harvesters from $54 \mathrm{~mW}$ and iron powder harvesters harvested at $77 \mathrm{~mW}[2,15]$. The C-core design made of ferrite material provided ease of installation and harvested $105.24 \mathrm{~mW}$ at a line current of 65.3 A [11]. Sordiashie et al. [16], for example, introduce an AMCC-4 core harvester for use in the built environment. Wang et al. [17] harvested about $20 \mathrm{~W}$ from a resonated harvester at a line current of $68 \mathrm{~A}$. Liu et al. [10] harvested $350 \mathrm{~mW}$ from $10 \mathrm{~A}$ line current which is sufficient for the operation of many sensors. White et al. [18] harvested $1.5 \mathrm{~W}$ of energy from a 100 A line current. When the silicon steel, nickel and nanocrystalline material cores were compared as the core material, the highest energy was found to be double nanocrystalline core harvesters [19]. The cold rolled silicon steel core decreased the air gap, increased the radial thickness, the inner radius, the core height and the yield of the harvester [9]. Core designs in different ways affect harvesting performance. For example; it has been stated that by extending two ends of the bow-shaped core like a bow tie, more magnetic flux can be directed from the air to the core and thus 15 times more energy is harvested [20]. The saturation of the core limits the tension induced in the windings. In electromagnetic harvesters, the increase of the line current to saturate the magnetic flux density of the core reduces the energy to be obtained from the harvester and disrupts the waveform of the induced voltage. Therefore, the saturation characteristics of the core material should be considered. The core saturation time can be reduced by a switch to be connected in parallel to the harvester coil, if the line current increases enough to feed the core, by shortly switching the coil ends of the switch and then opening it again [21]. As it is known, since the magnetic flux is less directed in air-core harvesters, the harvested power is very small and there are no saturation effects. However, it can be used in systems with very high line current. The air-core semicircular coil design gave better results than the full-circle, square and triangular design [12].

As a continuation of our previous studies [22-24], the design and implementation of the harvester sensor system was carried out in this study. The motivation of this study is to manufacture a new energy harvesting device with an original design to be used on power line. The contributions of the study can be written as follows: (a) comparison of results between numerical analysis and experimental results, (b) getting sensor data with high accuracy, (c) reducing production and maintenance costs, (d) ensuring operational continuity. The study is carried out in three stages. In the first stage, two different devices are formed to harvesting energy on the power line. In the second stage, the magnetic field harvesting devices are analyzed by utilizing the FEM in terms of design features. In addition, iron losses and induced voltage changes were 
investigated for different core materials. The last stage of this study is to check whether the system is data logger.

\section{MATERIAL METHOD}

The system, which is widely used for obtaining energy from the power line, is shown in Figure 1. This system consists of one or more electromagnetic harvesters, a power control circuit, sensor / sensor group, radio frequency $(\mathrm{RF})$ transmitter. Electromagnetic harvester provides the electrical energy needed by the power card (power control circuit, sensor, RF transmitter). The data received from the sensor or sensors are transferred to the receiver circuit via the RF transmitter.

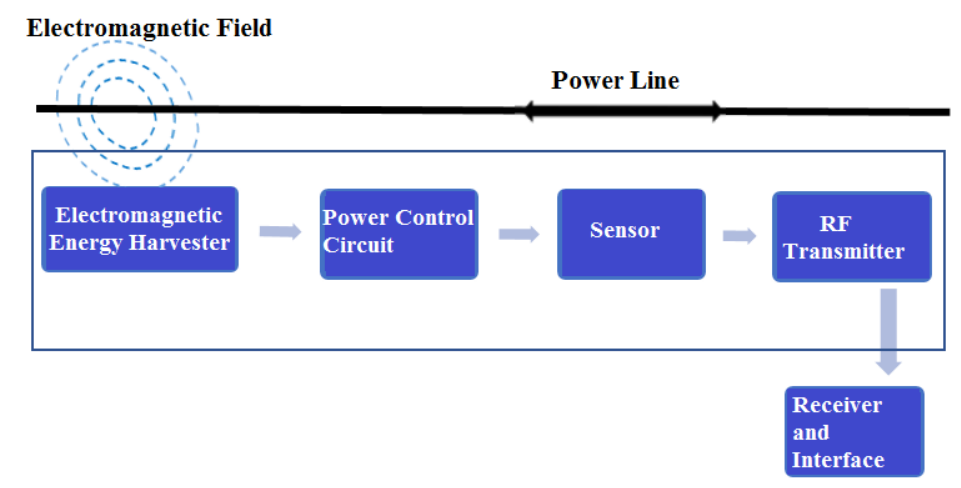

Figure 1. Data acquisition system with harvester

\subsection{Electromagnetic Energy Harvester}

The harvester models in the literature are generally shown in Figure 2. According to its geometry and structure, it was examined under two (2) main titles. When analyzed by geometry, it can be examined in four (4) groups as $\mathrm{C}$ type, $\mathrm{U}$ type, toroidal and other type. $\mathrm{C}$ type and $\mathrm{U}$ type cores provide ease of installation on the line, but their inductance is lower than toroidal. Apart from the traditional core models, cores defined as 'Other Type' such as solenoid, bow tie [20] and helical [25] are also designed for harvester applications. According to its structure, it can be examined in two groups such as air and ferromagnetic materials. Here, although the line current is high in air core harvesters, the power to be obtained is very low. For this reason, it is stated that the air core structure [12] is not suitable for harvesters. Nanocrystalline, amorphous and ferrite cores are most preferred in harvesting applications of these materials.

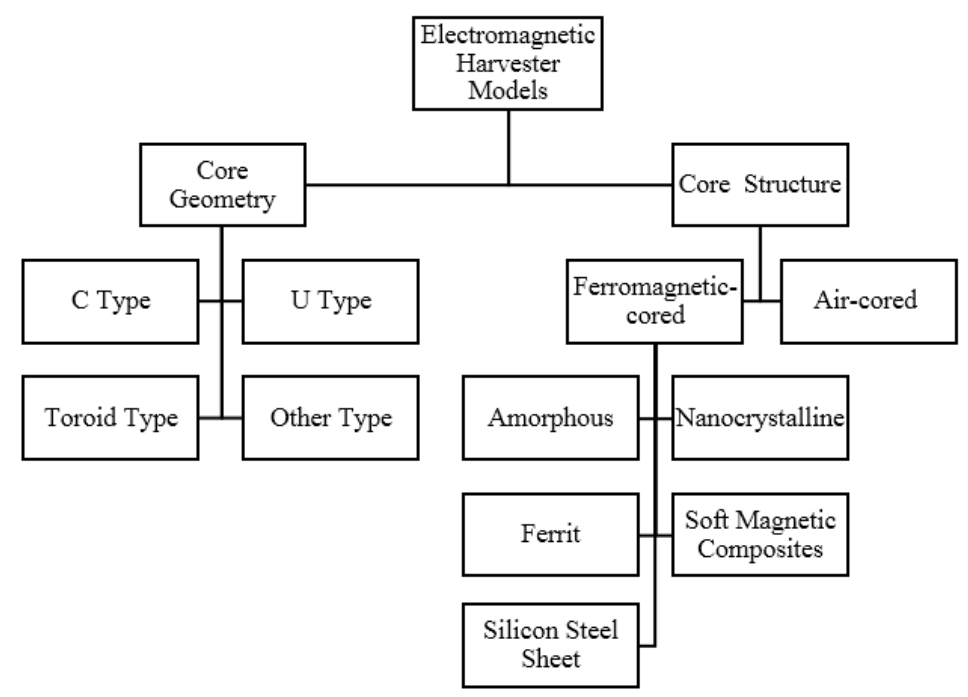

Figure 2. Structure of a simple artificial neural network 


\subsection{Harvesting Design Models}

In Figure 3 (a) and (b), drawings of core type models are given, where " $\mathrm{H}$ " indicates core height, "A" core outer width, "B" window width and "D" thickness. Amorphous material harvesters were studied for the core type geometries given in technical specifications in Table 1. Figure 3 shows the $\mathrm{C} 1$ and $\mathrm{C} 2$ models. In $\mathrm{C} 2$ model, the windings are connected in series.
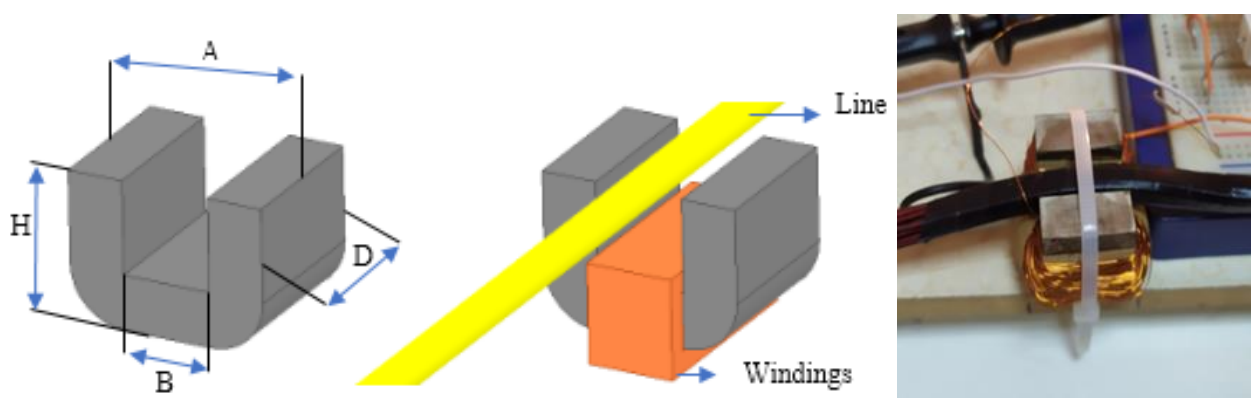

(a)
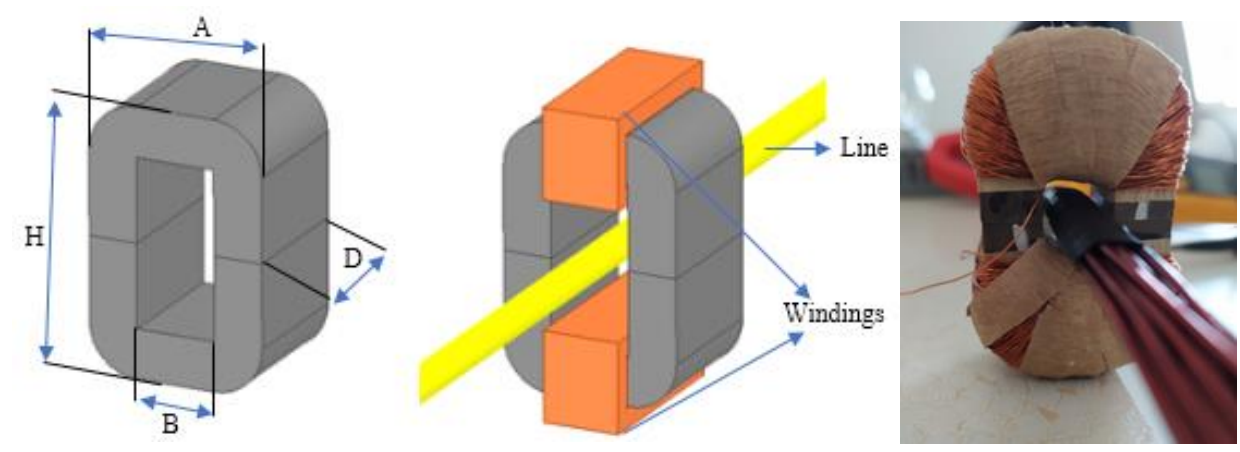

(b)

Figure 3. Core type models; (a) C1 core model, (b) C2 core model

For these models whose numerical analyses were made with Ansys Maxwell software, experiments were carried out by installing the experiment set shown in Figure 4. Then, experimental data and numerical analyses were compared.

Table 1. Technical specifications of core type geometries

\begin{tabular}{|l|l|l|l|l|l|l|l|l|l|}
\hline Models & $\begin{array}{l}\mathbf{A} \\
(\mathbf{m m})\end{array}$ & $\begin{array}{l}\mathbf{B} \\
(\mathbf{m m})\end{array}$ & $\begin{array}{l}\mathbf{D} \\
(\mathbf{m m})\end{array}$ & $\begin{array}{l}\mathbf{H} \\
(\mathbf{m m})\end{array}$ & $\begin{array}{l}\mathbf{N} \\
(\mathbf{t u r n})\end{array}$ & $\begin{array}{l}\text { Wire } \\
\text { Diameter } \\
(\mathbf{m m})\end{array}$ & $\begin{array}{l}\text { Calculated } \\
\mathbf{R d c} \\
(\mathbf{\Omega})\end{array}$ & $\begin{array}{l}\text { Measured } \\
\text { Rdc } \\
(\mathbf{\Omega})\end{array}$ & $\begin{array}{l}\text { Measured } \\
\mathbf{L}(\mathbf{H})\end{array}$ \\
\hline C1 & 31 & 11 & 20 & 25 & 800 & 0.25 & 17.11 & 21.2 & 0.063 \\
\hline C2 & 31 & 11 & 20 & 50 & 1600 & 0.25 & 34.21 & 42.4 & 0.126 \\
\hline
\end{tabular}


Core losses at various frequency and induction levels are measured using various excitation waveforms. Based on the measurements [26-27], the coefficients of the Steinmetz Equation (1) are estimated:

$$
P_{w}=k_{w}\left(f / f_{0}\right)^{\alpha}\left(B / B_{0}\right)^{\beta}
$$

Here $P_{w}$, core loss per unit weight, $f_{0}$ is the fundamental frequency $(1 \mathrm{~Hz}), B_{0}$ is the basic flux density (1 T). Also $k_{w}, \alpha$ and $\beta$ are Steinmetz coefficients obtained from experimental data. When the waveform is sinusoidal, the coefficients are taken as $k_{w}=0.003369, \alpha=1.301033, \beta=2.135959$ [27]. The general winding resistance calculation formula for a coil is given in Equation (2)

$$
R=\rho \frac{L_{B}}{S} N
$$

Here $\rho$ denotes the core resistance of the conductor $\left(1.72 \times 10^{-8} \Omega \mathrm{m}\right.$ for copper), the length of the $L_{B}$ winding, the number of windings $N$, and $S$ is the cross-sectional area of the conductor. The average magnetic flux path $\left(L_{\mathrm{mC} 1}\right)$ for $\mathrm{C} 1$ (single) model of core type cores is given in Equation (3)

$$
\begin{aligned}
& L_{\mathrm{mC} 1}=2 H+(\pi / 2+1)(A-B) . \\
& L_{\mathrm{mC} 2}=2 L_{\mathrm{mC} 1}+2 g .
\end{aligned}
$$

Here $\mathrm{H}$ indicates the core height, A core outer width and $\mathrm{B}$ window width. Of the core types, cores given in Equation (4), the average magnetic flux path $\left(L_{\mathrm{mC2}}\right)$ for the $\mathrm{C} 2$ (double) model will be twice the single model. However, attention should be paid here to the air $g$.

The set of experiments set up for the energy harvesting system is given in Figure 4. The materials included in this set of experiments are listed as load group, power line, harvesting cores. In order to pass current through the line, the load group consisting of incandescent lamps was connected in series in parallel in different ways and the line current was created and this current was measured by measuring with a clamp multimeter. The number of conductors in the line has been increased to increase the line current and the magnetic field density around the line. The line conductor is wound with multiple windings using a cable channel on a rectangular wooden floor. Cores in geometry $\mathrm{C}$ used for energy harvesting are placed on the line, respectively. In this set of experiments (Figure 4), the voltages and currents harvested at different loads from the harvesters were measured and recorded with multimeters.

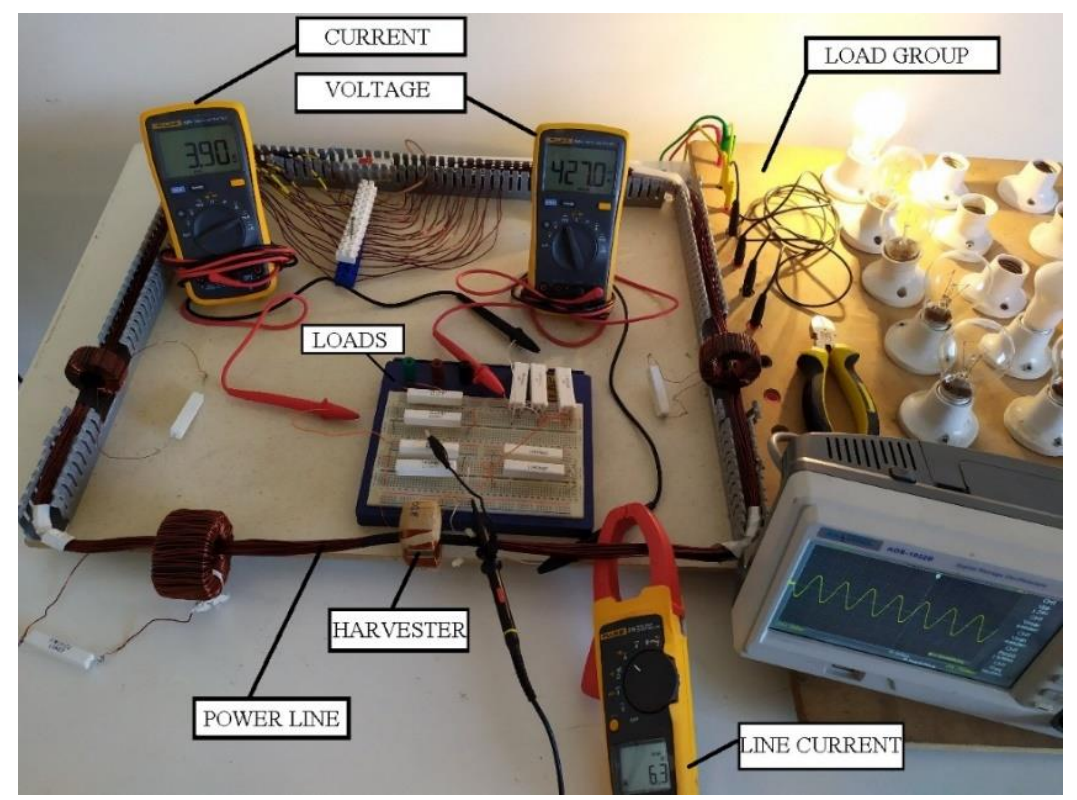

(a) 


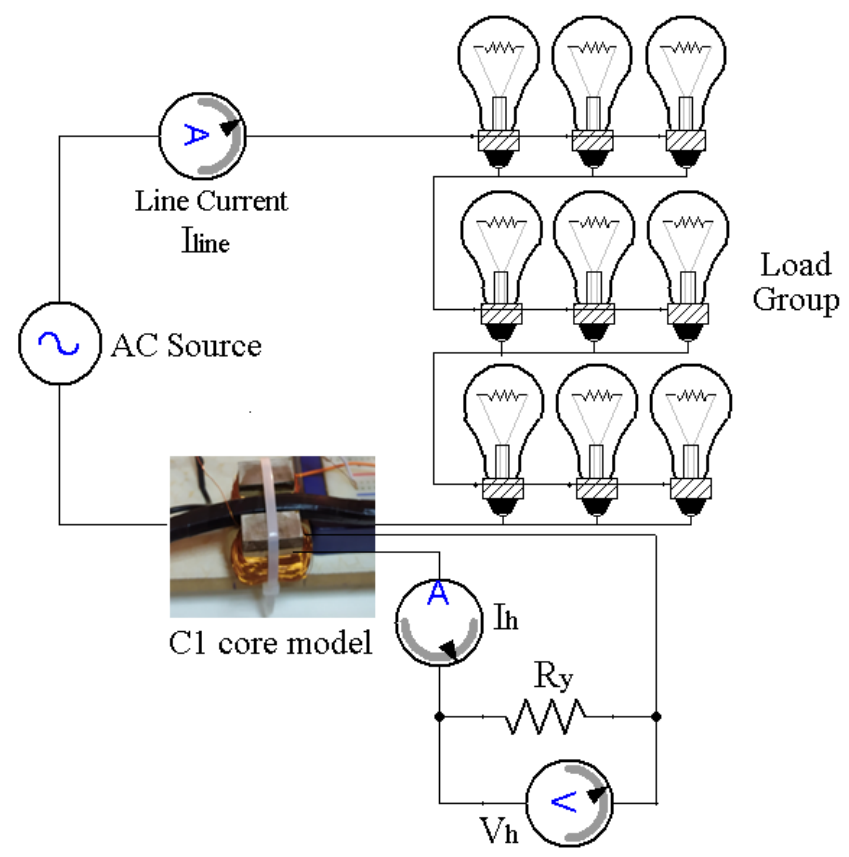

(b)

Figure 4. (a) Preliminary test kit for harvesters, (b) Electrical circuit diagram of the preliminary test kit [22]

\subsection{Numerical Analyses with Ansys Maxwell Software}

It is easy to solve complex structures, especially inhomogeneous structures, by finite element method (FEM). This method is based on the logic of finding the main solution by dividing the complex problems into simple known infrastructures and solving each of them separately. As can be expected, more sensitive solutions can be made by increasing the number of infrastructures. In finite element analysis, a complex physical system is transformed and solved into a mathematical model that can be subdivided ANSYS, NASTRAN, ABAQUS, COSMOS etc. working in this logic today. Computer aided commercial software has become indispensable in the analysis and design of industrial applications.

In this study, ANSYS Maxwell 3D commercial software, which is the most used in the literature, has been chosen because of its features such as having a wide drawing infrastructure for numerical analysis, transient state, magnetostatic state, and Eddy currents. This program creates sub-regions in the structure by dividing the structure into multiple tetrahedron pieces to determine the magnetic field in non-homogeneous structures. It determines the area of each region with separate polynomials for each sub-region [28]. The sub-zoning process is called meshing, the sub-zones are finite elements, and the sum of these elements is the finite element network. The more finite elements in an analysis, the more realistic the results will be. The software calculates the magnetic field intensity at the midpoints of all defined finite elements using current density. In case the core material is not linear, analysis is carried out using the B-H curve with a linear approach with the Newton-Raphson method. After the analysis is completed, error analysis is carried out and the solvent continues to analyze continuously until the determined criteria are fulfilled by separating the most faulty finite element repeatedly. As a result, inductance value, current density, magnetic field intensity, magnetic flux density, losses and forces can be obtained for materials determined with this software $[28,29]$.

\subsubsection{Transient state analysis of harvesting models}

Similar to the continuous state analysis, the coordinate plane of the model to be solved is determined. Solution method is chosen as transient. The harvested model is drawn. Line current is drawn by taking into 
account Ampere's law. In order to model the line current, the line was chosen to be much larger than the rectangular harvester model. Because the magnetic field intensity in the edge currents of the rectangular line model is not intended to affect the harvester model. The line current is defined in the line current terminal as the line current values to be performed in the experiment. This definition is defined as sign $I=$ $I_{m} \sin (\omega t)$ since the current passing through the line changes as a sinusoidal wave. Winding definitions are defined to give the induced voltage. In addition, the analyses related to the loading of the harvester were carried out using the external circuit model. When the line current of Model C1 and Model C2 are taken as 6.2 A for the different core materials (Table 2), the losses in the core and the induced voltage changes in the windings are examined via Ansys Maxwell Transient 3D.

Table 2. Core loss and voltage for different core materials

\begin{tabular}{|c|c|c|c|c|c|}
\hline \multirow[t]{2}{*}{ Materials } & \multirow{2}{*}{$\begin{array}{l}\text { Core Loss Coefficient } \\
\left(\mathrm{W} / \mathbf{m}^{3}\right)\end{array}$} & \multicolumn{2}{|c|}{ C1 core model } & \multicolumn{2}{|c|}{ C2 core model } \\
\hline & & $\begin{array}{l}\text { Core Loss } \\
(\mathbf{u W})\end{array}$ & $\begin{array}{l}\text { Vrms } \\
(\mathbf{m V})\end{array}$ & $\begin{array}{l}\text { Core Loss } \\
(\mathbf{m W})\end{array}$ & $\begin{array}{l}\text { Vrms } \\
\text { (V) }\end{array}$ \\
\hline $\begin{array}{l}\text { Amorphous } \\
\text { 2605SA1 }\end{array}$ & $\begin{array}{l}\mathrm{Kh}=40.43478638 \\
\mathrm{Kc}=0.0007908339 \\
\mathrm{Ke}=0.509838205741\end{array}$ & 0.561 & 116.79 & 3.87 & 17.50 \\
\hline $\begin{array}{l}\text { M43 steel (nongrain } \\
\text { oriented steel) }\end{array}$ & $\begin{array}{l}\mathrm{Kh}=222.8 \\
\mathrm{Kc}=0.908 \\
\mathrm{Ke}=2.5\end{array}$ & 3.15 & 102.8 & 9.07 & 11.23 \\
\hline $\begin{array}{l}\text { M5 steel (grain oriented } \\
\text { steel) }\end{array}$ & $\begin{array}{l}\mathrm{Kh}=59.594588735 \\
\mathrm{Kc}=0.2960881320 \\
\mathrm{Ke}=0\end{array}$ & 0.396 & 116.56 & 4.5 & 15.09 \\
\hline Somaloy (SMC) $10003 p$ & $\begin{array}{l}\mathrm{Kh}=555.154725889691 \\
\mathrm{Kc}=0.00161909522837124 \\
\mathrm{Ke}=15.7211874728827\end{array}$ & 12.91 & 110.59 & 4.42 & 4.38 \\
\hline Nanocrystalline & $\begin{array}{l}\mathrm{Kh}=5.03139476001441 \\
\mathrm{Kc}= \\
0.000430896041650968 \\
\mathrm{Ke}=0.285713212221422\end{array}$ & 0.21 & 116.79 & 0.73 & 17.18 \\
\hline Ferit core PC90 & $\begin{array}{l}\mathrm{Cm}=6.069249660 \\
\mathrm{X}=1.31093941392 \\
\mathrm{Y}=2.14843567195\end{array}$ & 0.0459 & 114.75 & 0.472 & 11.4 \\
\hline
\end{tabular}

As a result of the analysis carried out with Ansys Maxwell, for Model C1, the effects of leakage fluxes are neglected and the core loss is calculated by using the Steinmetz formula given in Equation (1) with the sinusoidal wave loss coefficients. This loss was found on average $0.62 \mu \mathrm{W}$. Maximum core loss was found to be $1 \mu \mathrm{W}$ in three-dimensional analysis. With the Steinmetz formula given in Equation (1) for Model C2, the average core loss was calculated as $8.6 \mathrm{~mW}$. Maximum core losses of Model C2 performed with Ansys Maxwell were found to be $6.3 \mathrm{~mW}$ in three-dimensional (3D) analysis. 


\subsubsection{Steady state analysis of harvesting models}

The coordinate plane of the model under consideration is determined. The solution method is chosen as steady state (magnetostatic). The harvested model is drawn. Line current is drawn by taking into account Ampere's law. In order to model the line current, the line is chosen to be much larger than the harvester model in rectangular shape. Because the magnetic field intensity in the edge currents of the rectangular line model is not intended to affect the harvester model. The line current is defined in the line current terminal as the line current values to be performed in the experiment. Solutions were realized by meshing the kernel of the harvester model. Flux density changes occurring in the nucleus in line currents are examined.

The line current of Model C1, whose technical features are given in Table 1, is defined as $6.2 \mathrm{~A}$ and static magnetic analysis is carried out with Ansys Maxwell. In Figure 5, magnetic flux density change and flux lines of $\mathrm{C} 1$ and $\mathrm{C} 2$ models are given as a result of analysis.

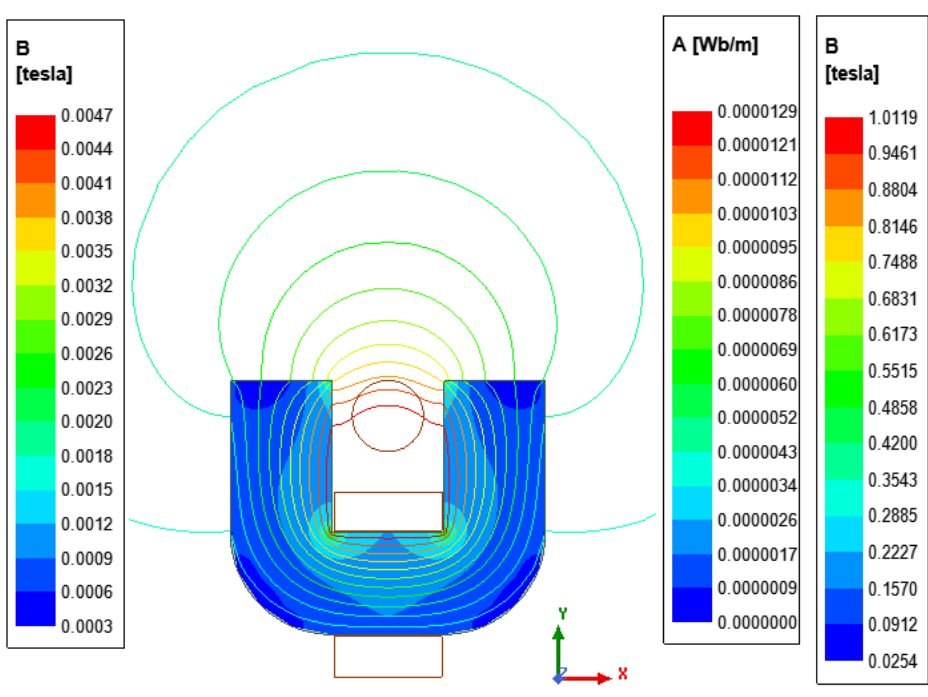

(a)

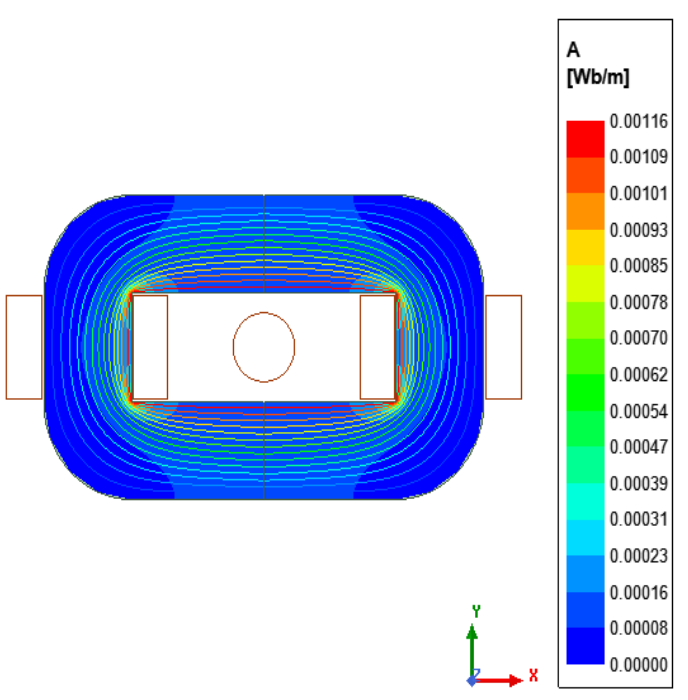

(b)

Figure 5. (a) Model C1 (b) Model C2 magnetic flux density change and flux lines

As can be seen in Figure $5 \mathrm{C}$, the magnetic flux density has decreased significantly due to the high air gap. The average magnetic flux density in $6.2 \mathrm{~A}$ line current is $1.2 \mathrm{mT}$. This value is very small considering the saturation magnetic flux density of the core. In this case, it can be thought that saturation effects will not occur in high line currents compared to other core models.

The magnetic flux completes its circuit from the inner regions of the core material and the magnetic flux density decreases towards the outer regions of the core. In addition, the flux in the areas close to the harvester core of the conductor carrying the line current shortly completes its circuit. Increasing the air gap will increase reluctance in the magnetic circuit, therefore the effective magnetic flux will decrease. The model was tightly tied with a cable tie during the experiment to reduce the air gap. As can be seen in the C2 model in Figure 5, the flux density is concentrated in the core inner regions.

The corner points of amorphous $\mathrm{C}$ type cores are produced curved to reduce magnetic saturation effects. This situation is also taken into account in the simulation model. In the simulation study, the maximum flux density was found to be $1.01 \mathrm{~T}$. When the flux lines are taken into consideration, it is seen that a small amount of leakage fluxes are formed in the corners of the core. 


\subsection{RF Transceiver, Power Control and Sensors Board}

The nRF24L01 transceiver module used in the circuit uses the $2.4 \mathrm{GHz}$ band. If it is used outdoors and at low baud rate, its range can be up to 100 meters (Datasheet, nRF24L01). In the designed circuit, this distance was increased up to 1000 meters with the module signal booster (LNA-Low Noise Amplifer). The power consumption of this module is around $12 \mathrm{~mA}$, which is lower than just one LED during transmission. The voltage of the module is between $1.9 \mathrm{~V}$ and $3.6 \mathrm{~V}$, but the pins tolerate $5 \mathrm{~V}$ voltage so we can easily connect it to a microcontroller without using any logic level converter [30]. The prepared circuit is given in Figure 6. The working principle of the circuit converts the harvested AC voltage to DC voltage through DB207S bridge diode rectifier circuit. With the help of a $12 \mathrm{~V}$ Zener diode, the voltage is fixed to a certain voltage. The battery charging circuit is installed with the TP4056 chip and charges the Li-Po battery with a $1300 \mathrm{mAh}$ capacity connected to the system. The charged voltage is raised with the help of the DC-DC amplifier circuit with MT3608 chip and produces the voltage level required for the operation of the system.

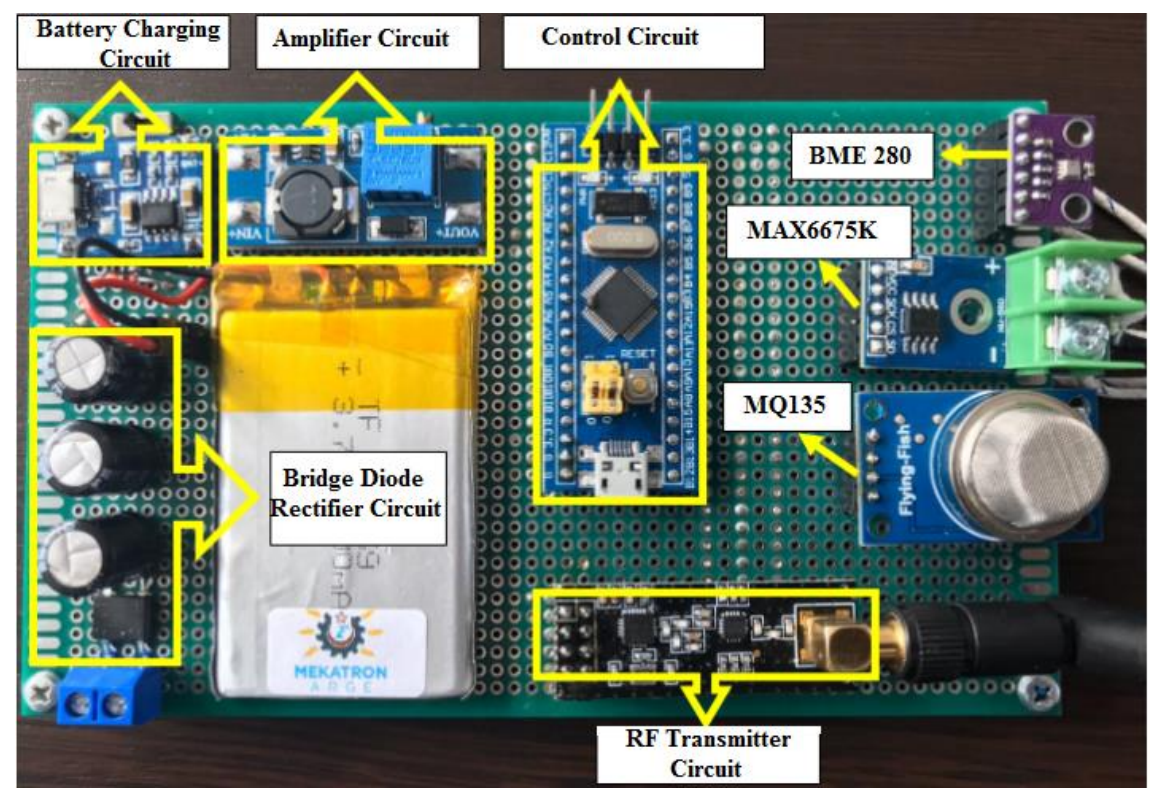

(a)

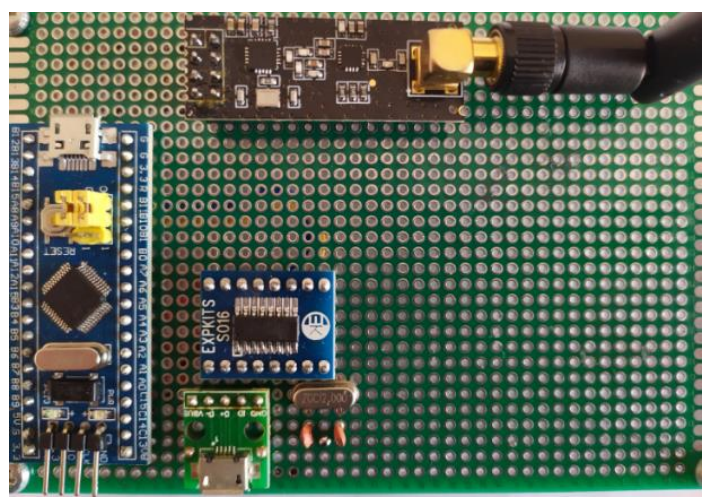

(b)

Figure 6. (a) Power control, sensors and RF transmitter circuit (b) RF receiver circuit

With the BME280 sensor shown in Figure 6(a) and given some technical features in Table 3, temperaturehumidity-pressure-altitude, transformer oil temperature with MAX6675 thermocouple and air quality data 
with MQ135 sensor are interpreted and processed by the microcontroller via RF module transmitter circuit sent to the receiver circuit. The receiver circuit shown in Figure 6(b) interprets the data from RF and transfers it to the serial port of the computer with the help of CH340G chip at 115200 baud rate.

Table 3. Some technical features of the sensors [29]

\begin{tabular}{|c|c|c|c|c|c|}
\hline Character & Code & $\begin{array}{c}\text { Supply } \\
\text { Voltage } \\
(+V)\end{array}$ & $\begin{array}{c}\text { Supply } \\
\text { Current } \\
(\mathbf{m A})\end{array}$ & $\begin{array}{c}\text { Power } \\
(\mathbf{m W})\end{array}$ & Manufacturer \\
\hline Humidity & \multirow{4}{*}{ BME280 } & \multirow{4}{*}{3.3} & 0.340 & 1.2 & \multirow{4}{*}{ BOSCH } \\
\hline Temperature & & & 0.350 & 1.3 & \\
\hline Altitude & & & - & - & \\
\hline Pressure & & & 0.714 & 2.6 & \\
\hline Thermocouple & MAX6675 & 3.3 & 0.7 & 3.5 & MAXIM \\
\hline Ammoniac & \multirow{3}{*}{ MQ135 } & \multirow{3}{*}{5} & \multirow{3}{*}{160} & \multirow{3}{*}{800} & \multirow{3}{*}{ OLIMEX } \\
\hline Smoke & & & & & \\
\hline Sulphur & & & & & \\
\hline
\end{tabular}

\subsection{Sensor-Computer Interface Development}

The main page of the designed user-friendly graphical interface program is shown in Figure 7. The PC interface program prepared as GUI (Graphical User Interface) sorts the data coming from the serial port into time and data coordinates and lists them according to time and graphically. The interface program has $\mathrm{COM}$ port connection settings and registration period options on the main screen. The program allows to save the recorded sensor data together with the time information in *.xlsx (excel) format or *.png (vector image) format in the graphics for each sensor.

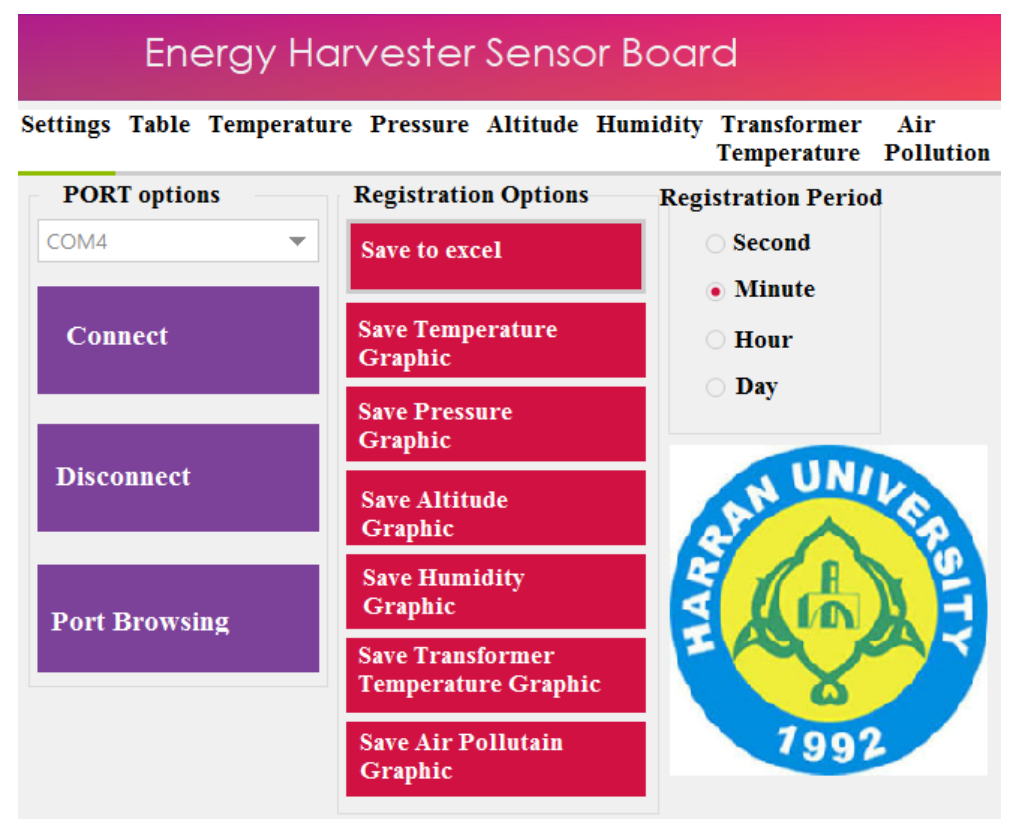

Figure 7. PC Interface program 
The computer interface consists of eight (8) tabs. We can summarize them briefly as follows;

- Settings: Port options, connecting to the transmitter, disconnecting and saving and exporting data can be done from this main tab.

- Table: In this tab, all sensor data can be seen in the time interval set in table form according to time.

- Temperature: In this tab, the graph of the incoming temperature data can be seen in the time interval set from the BME280 sensor. The sensor (BME280 data card can be examined in the appendix) can measure between $-40{ }^{\circ} \mathrm{C}$ and $+85^{\circ} \mathrm{C}$.

- Pressure: In this tab, the graphic of the incoming air pressure data can be seen in the time interval set from the BME280 sensor. The sensor (BME280 data card can be examined in the annexes) can measure air pressure between $300 \mathrm{hPA}$ and $1100 \mathrm{hPA}$.

- Altitude: In this tab, you can see the graph of altitude data coming from sea level in the time interval set from BME280 sensor. The sensor (BME280 data card can be examined in the appendices) can give the altitude information between 0 and $1000 \mathrm{~m}$.

- Humidity: In this tab, the graph of the relative humidity data in the air coming from the BME280 sensor can be seen within the time interval set. The sensor (BME280 data card can be examined in the appendix) can measure the relative humidity between $10 \%$ and $90 \%$.

- Transformer temperature: In this tab, the graph of the temperature information received from the Transformer oil pocket can be seen within the time interval set from the MAX6675K thermocouple sensor. The sensor (MAX6675K data card can be examined in the appendix) can measure temperature between $0{ }^{\circ} \mathrm{C}$ and $+700^{\circ} \mathrm{C}$.

- Air pollution: In this tab, the harmful particle graphic in the air can be taken from the MQ135 air quality measurement sensor in ppm (particule per million) within the set time period. The sensor (MQ135 data card can be examined in the appendices) can measure the amount of NH3 (ammonia) between $10 \mathrm{ppm}$ and $300 \mathrm{ppm}$ of air, Benzene between $10 \mathrm{ppm}$ and $1000 \mathrm{ppm}$, and Alcohol between $10 \mathrm{ppm}$ and $300 \mathrm{ppm}$.

Calibration of the measurement data taken from the computer interface program has not been done, but during the industrial tests, the air temperature, humidity and transformer temperature measurement data at the interface have been compared with the calibrated measuring instruments of the company. The amount of deviation between them is given in Chapter 3 .

\section{THE RESEARCH FINDINGS AND DISCUSSION}

\subsection{Preliminary Experiment Studies}

The experiments of amorphous core type models were carried out in the experiment set given in Figure 4, where the power line was modeled. $3 \mathrm{~A}, 6.2 \mathrm{~A}$ and $9.2 \mathrm{~A}$ were passed through the line, and the harvester load was changed between $11 \Omega$ and $330 \Omega$, and the current and voltage harvested at different line currents and different loads were measured and recorded. The harvested power is calculated by multiplying the harvested current and voltage. Current, voltage and power graphs that are harvested according to the load of the data saved in the Excel file are obtained. When the line current of Model C1 is $6.2 \mathrm{~A}$, the voltage change induced during idle operation is compared with Ansys Maxwell software and experiment results in Figure 8. 


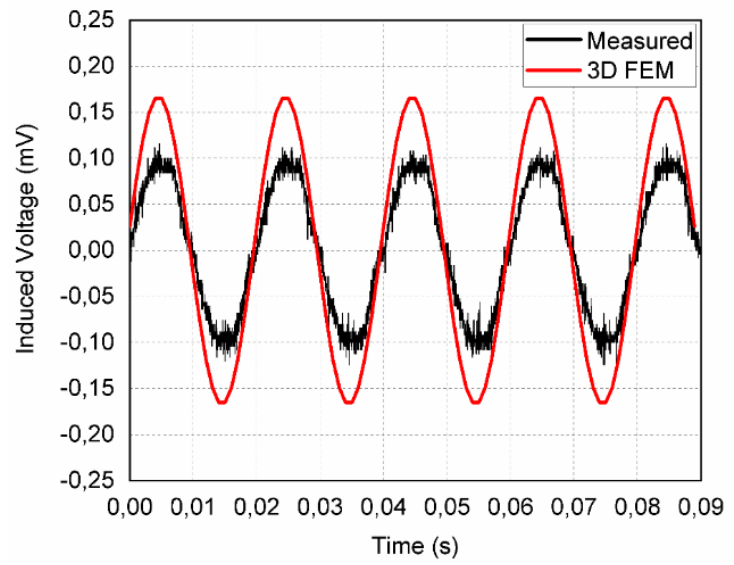

Figure 8. 3D FEM predicted and measured voltage for Model C1

According to the application and simulation results, the waveform has the same properties as the waveform of the line current. In the simulation study, the peak value of the induced voltage was found to be $70 \mathrm{mV}$. In practice, the peak value of the induced voltage was measured as $80 \mathrm{mV}$. Simulation and application results seem to be compatible with each other. In the experiments for Model $\mathrm{C} 1$, the graph of the change of the harvested power $\left(P_{h}\right)$ and the harvested voltage $\left(V_{h}\right)$ according to the change of the line current $\left(I_{\text {line }}\right)$ and load resistance $\left(R_{y}\right)$ are given in Figure 9.

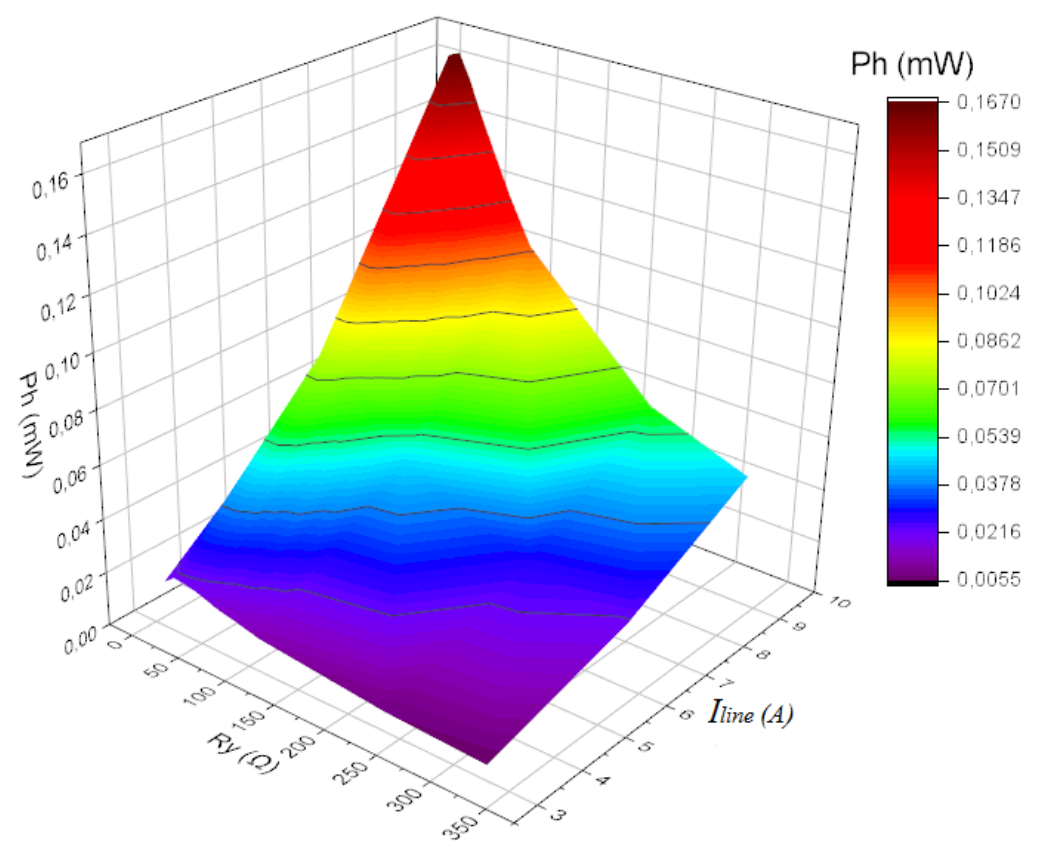

(a) 


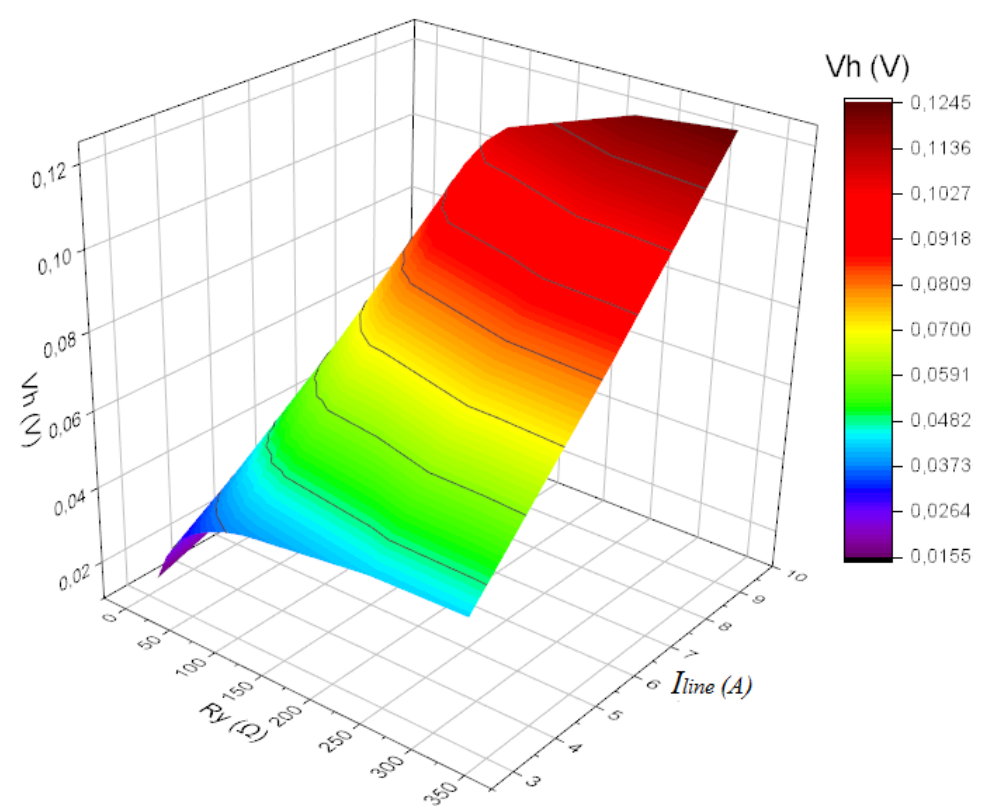

(b)

Figure 9. (a) Harvested power change graph for Model Cl b) Harvested voltage change graph for Model

C1

The maximum harvested power at $3 \mathrm{~A}$ line current was measured as $0.02 \mathrm{~mW}$ at $22 \Omega$ load resistance. The maximum power at $6.2 \mathrm{~A}$ line current was measured at $33 \Omega$ load resistance as $0.07 \mathrm{~mW}$. The maximum power at a line current of 9.2 A was measured as $0.16 \mathrm{~mW}$ at $33 \Omega$ load resistance. As seen from the experimental data, as the line current increases, the load resistance at which the maximum power harvested occurs increases. However, it can be seen as an advantage in terms of being used in very high line currents that it will not be saturated even at very high line currents. In addition, it was observed in the experiments for Model $\mathrm{C} 1$ that the voltage harvested increases as the load increases in the line currents. A voltage of $0.12 \mathrm{~V}$ at $330 \Omega$ load was harvested at 9.2 A line current. When the line current of Model $\mathrm{C} 2$ is $6.2 \mathrm{~A}$, the voltage change induced in the idle state is compared with the Ansys Maxwell software and the experiment results in Figure 10.

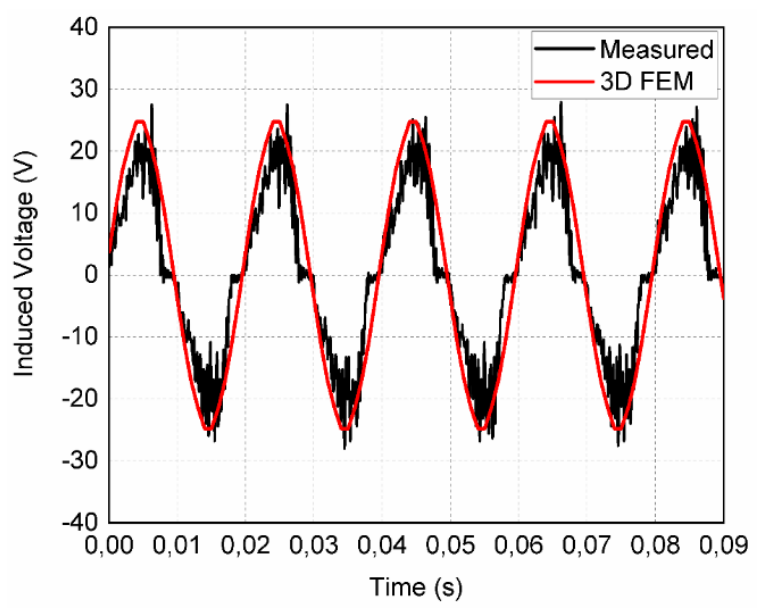

Figure 10. 3D FEM predicted and measured voltage for Model C2

According to the application and simulation results, the waveform has the same properties as the waveform of the line current. In the simulation study, the peak value of the induced voltage was found to be $16 \mathrm{~V}$. In practice, the peak value of the induced voltage was measured as $20 \mathrm{~V}$. Simulation and application results seem to be compatible with each other. In the experiments for Model C2, the graph of the change of the 
harvested power $\left(P_{h}\right)$ and the harvested voltage $\left(V_{h}\right)$ according to the change of the line current $\left(I_{\text {line }}\right)$ and load resistance $\left(R_{y}\right)$ are given in Figure 11.

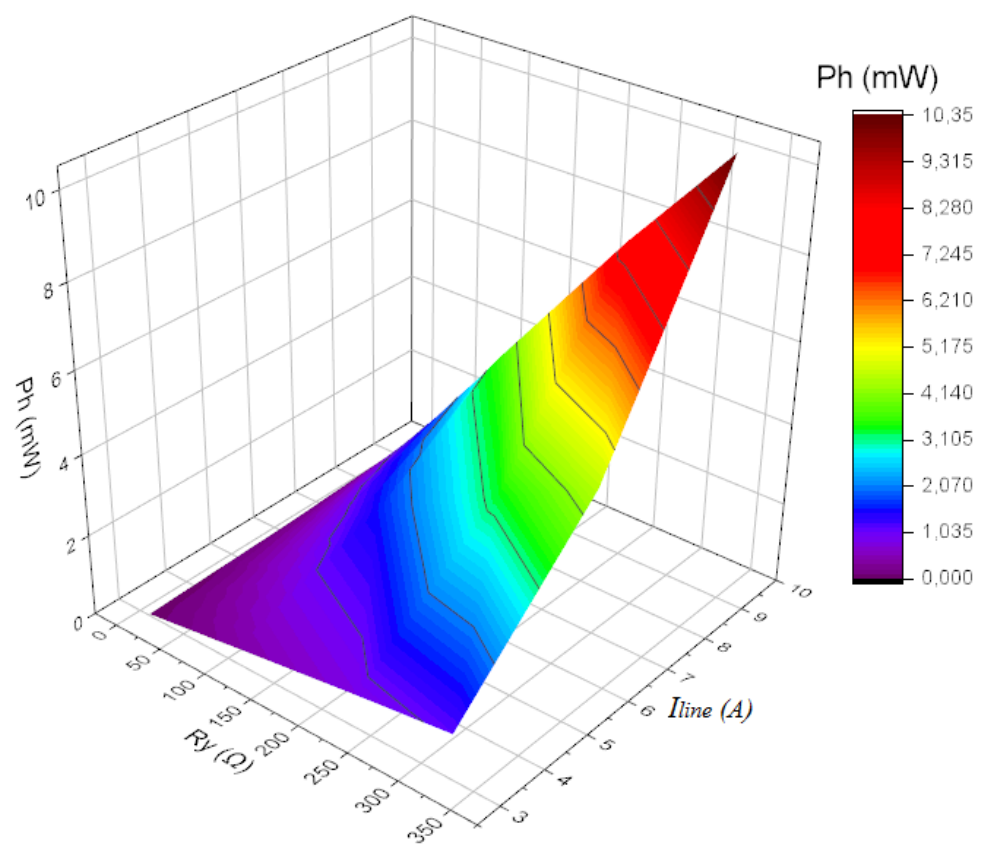

(a)

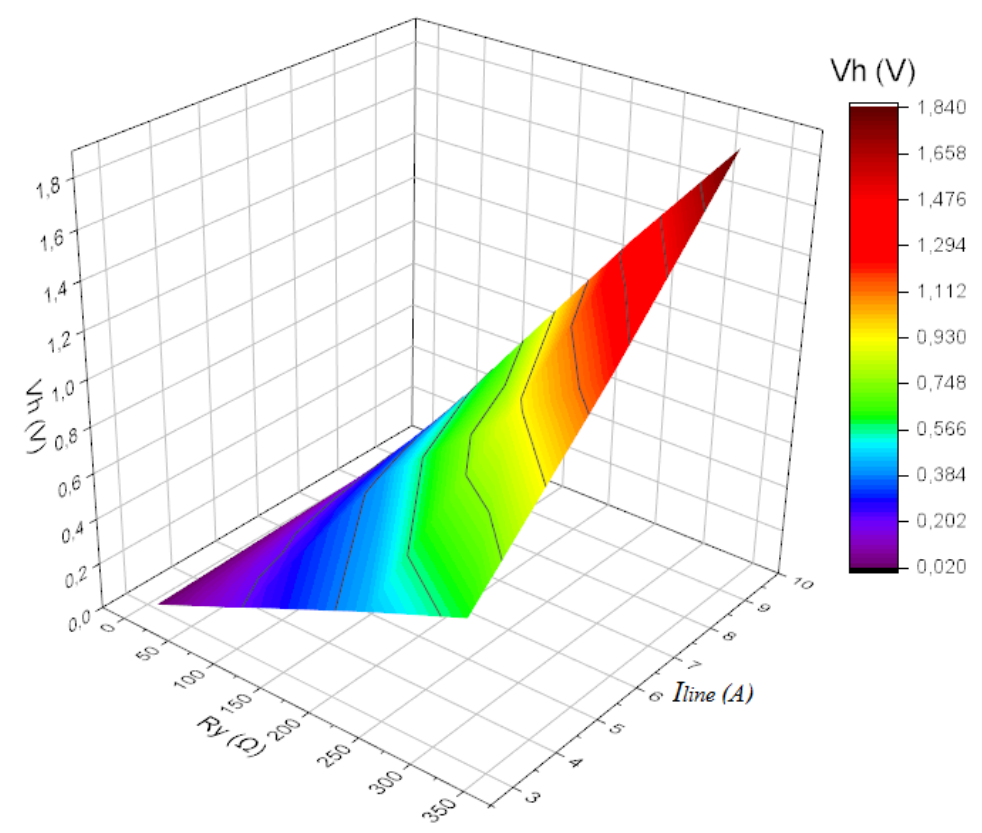

(b)

Figure 11. (a) Harvested power change graph for Model C2 b) Harvested voltage change graph for

\section{Model C2}

According to the experimental data of Model C2, the power has increased continuously despite the increase of the harvester load. Despite the increase in the load of the harvester in the experiment, the harvested power has increased continuously due to the continuous increase in the harvested voltage. The highest harvested power in all line currents was measured at $330 \Omega$ load resistance, the highest rated resistor in the test set. It was measured as $1.12 \mathrm{~mW}$ in $3 \mathrm{~A}$ line current, $4.5 \mathrm{~mW}$ in $6.2 \mathrm{~A}$ line current, $10.31 \mathrm{~mW}$ in $9.2 \mathrm{~A}$ 
line current. Although the volume of model $\mathrm{C} 2$ increased 2 times compared to model $\mathrm{C} 1$, approximately 200 times more energy was harvested in the same line current than $\mathrm{C} 1$ model. The biggest reason for this result comes from the decrease in the air gap in the $\mathrm{C} 2$ model (the considerably reduced magnetic reluctance) and the effective magnetic flux increasingly completing its circuit over the core. The highest harvested voltage in all line currents was measured at $330 \Omega$ load resistance, the highest rated resistance in the test set. It was measured as $0.61 \mathrm{~V}$ in $3 \mathrm{~A}$ line current, $1.21 \mathrm{~V}$ in $6.2 \mathrm{~A}$ line current, $1.84 \mathrm{~V}$ in $9.2 \mathrm{~A}$ line current.

\subsection{Field Test Application}

The 3-phase oil immersed type transformer with the brand of Meksan Transformer was used in the test carried out in the company. The transformer was operated as in the experiment of "finding short circuit impedance and load losses (TS EN ISO / IEC 60076-1)" to ensure proper line current. In this experiment, the low voltage side of the transformer can be shorted to draw current up to the rated current by the high voltage. With the technical infrastructure of the company, the rated current can be increased gradually. Industrial test is shown in Figure 12.

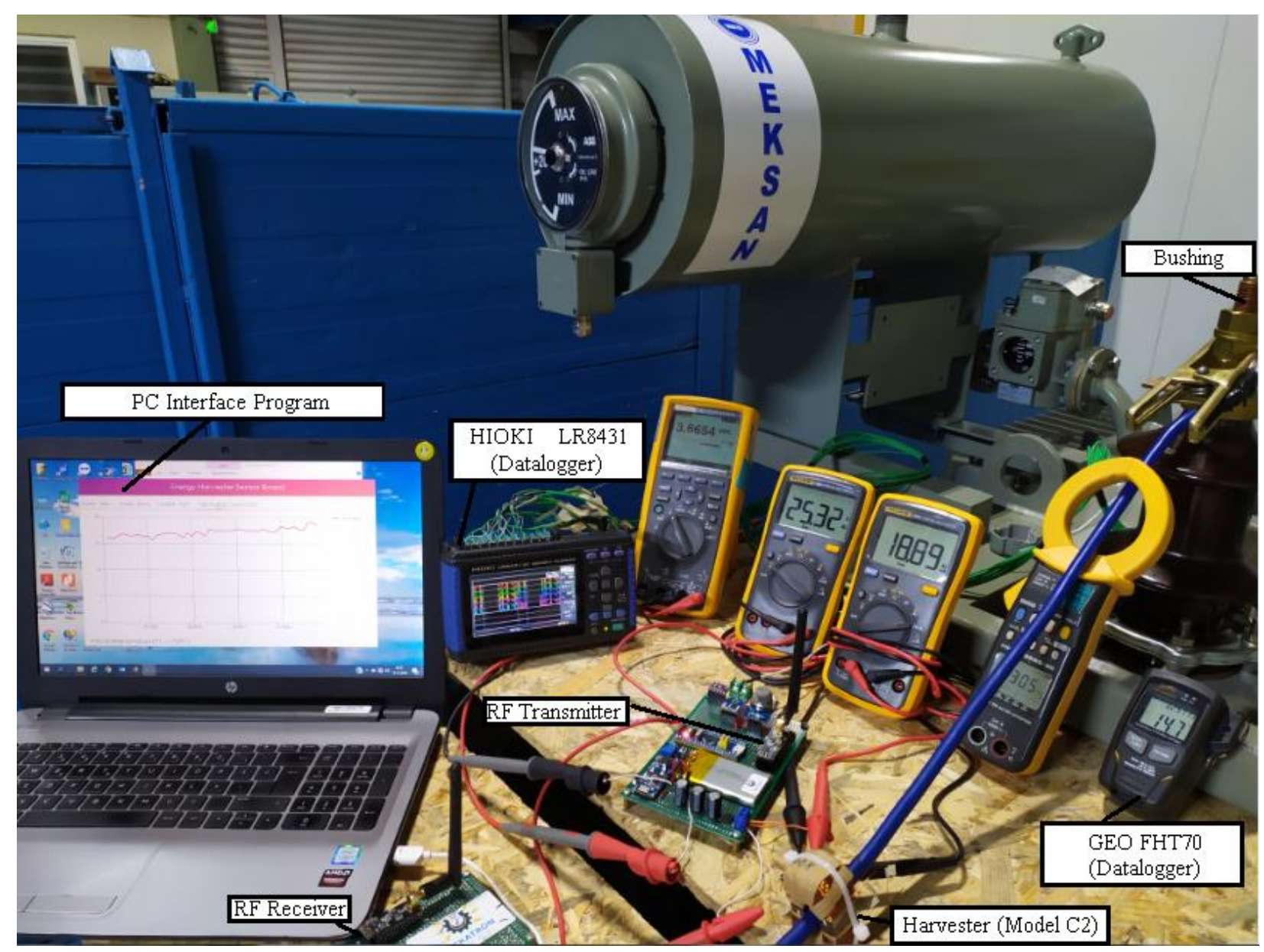

Figure 12. Industrial test

Before the industrial test, the harvester was firmly attached to the 'A' phase of the transformer by cable tie. For different line currents, the voltage taken from the battery charging circuit, the line current, the voltage 
harvested from the harvester, the current were measured and the power was calculated. The data obtained are given in Table 4. Here, the no-load condition is considered as the status of the Li-Po battery removed from the charging circuit sockets, the loaded state is considered as the operating state of the entire system, where the Li-Po battery is connected to the sockets of the charging circuit. Since the rectifier circuit's operating input voltage is between $20 \mathrm{~V}$ and $50 \mathrm{~V}$, it is determined that the ideal line current for the circuit is around $30 \mathrm{~A}$.

Table 4. Industrial test data

\begin{tabular}{|c|c|c|c|c|c|}
\hline $\begin{array}{c}\text { Loading } \\
\text { Status }\end{array}$ & $\begin{array}{c}\text { Line } \\
\text { Curren } \\
\mathbf{t}(\mathbf{A})\end{array}$ & $\begin{array}{c}\text { Battery } \\
\text { Charging } \\
\text { Voltage } \\
\mathbf{( V )}\end{array}$ & $\begin{array}{c}\text { Harvested } \\
\text { Voltage } \\
(\mathbf{V})\end{array}$ & $\begin{array}{c}\text { Harvested } \\
\text { Current } \\
(\mathbf{m A} \mathbf{)}\end{array}$ & $\begin{array}{c}\text { Harvested } \\
\text { Power } \\
(\mathbf{m W})\end{array}$ \\
\hline No Load & 10.60 & 3.71 & 11.84 & 5.32 & 62.99 \\
\hline No Load & 17.30 & 5.07 & 21.84 & 8.24 & 179.96 \\
\hline No Load & 21.10 & 5.02 & 25.35 & 10.62 & 269.22 \\
\hline No Load & 25.10 & 5.20 & 27.04 & 12.32 & 333.13 \\
\hline No Load & 30.50 & 5.10 & 31.54 & 14.45 & 455.75 \\
\hline At Load & 30.50 & 3.66 & 25.32 & 18.89 & 478.29 \\
\hline
\end{tabular}

In the industrial test setup (Figure 12), the line current passing through the bushing was adjusted to $30.5 \mathrm{~A}$ and the system was operated with all its components. The harvester started to charge the battery by harvesting $478.29 \mathrm{~mW}$ of power at 30.5 A line current. The system was run for more than one (1) hour in an industrial test run. Air temperature, pressure, altitude, humidity, transformer temperature, air pollution change data were obtained from the sensors in one-minute periods. Hioki LR8431, which the company uses for transformer temperature measurement, has been compared with the data obtained from the designed system (Table 5).

Table 5. Comparison of sensor data

\begin{tabular}{|c|c|c|c|c|c|c|c|c|}
\hline \multicolumn{2}{|c|}{ Transformer Temperature $\left({ }^{\circ} \mathbf{C}\right)$} & \multicolumn{3}{c|}{ Temperature $\left({ }^{\circ}\right.$ C) } & \multicolumn{3}{c|}{ Humidity (\%) } \\
\hline $\begin{array}{c}\text { Hioki } \\
\text { LR8431 }\end{array}$ & $\begin{array}{c}\text { Designed } \\
\text { Circuit }\end{array}$ & $\begin{array}{c}\text { Difference } \\
\text { \% }\end{array}$ & $\begin{array}{c}\text { Geo } \\
\text { FHT 70 }\end{array}$ & $\begin{array}{c}\text { Designed } \\
\text { Circuit }\end{array}$ & $\begin{array}{c}\text { Difference } \\
\text { \% }\end{array}$ & $\begin{array}{c}\text { Geo } \\
\text { FHT 70 }\end{array}$ & $\begin{array}{c}\text { Designed } \\
\text { Circuit }\end{array}$ & $\begin{array}{c}\text { Difference } \\
\%\end{array}$ \\
\hline 15.50 & 16.25 & 4.84 & 14.30 & 13.86 & -3.08 & 60.80 & 55.10 & -9.37 \\
\hline 15.30 & 16.00 & 4.58 & 14.60 & 14.29 & -2.12 & 58.80 & 53.85 & -8.42 \\
\hline 15.10 & 15.75 & 4.30 & 14.80 & 14.63 & -1.15 & 58.80 & 53.81 & -8.49 \\
\hline 15.20 & 15.75 & 3.62 & 14.70 & 14.28 & -2.86 & 57.90 & 52.57 & -9.21 \\
\hline 16.40 & 17.00 & 3.66 & 14.80 & 14.63 & -1.15 & 58.80 & 52.77 & -10.26 \\
\hline 16.60 & 17.25 & 3.92 & 14.80 & 14.75 & -0.34 & 58.80 & 52.57 & -10.60 \\
\hline 16.80 & 17.50 & 4.17 & 14.80 & 15.17 & 2.50 & 57.10 & 51.32 & -10.12 \\
\hline 17.00 & 17.75 & 4.41 & 14.90 & 15.22 & 2.15 & 58.80 & 51.17 & -12.98 \\
\hline 17.00 & 17.75 & 4.41 & 14.90 & 15.17 & 1.81 & 58.70 & 51.07 & -13.00 \\
\hline 22.70 & 24.00 & 5.73 & 14.90 & 15.23 & 2.21 & 58.70 & 50.95 & -13.20 \\
\hline 19.20 & 20.25 & 5.47 & 14.80 & 15.26 & 3.11 & 58.40 & 50.72 & -13.15 \\
\hline
\end{tabular}


It was observed that there was a maximum of $3.11 \%$ difference in air temperature measurement and $5.73 \%$ difference in transformer temperature measurement. This difference in transformer temperature measurement is due to the thermal double sensitivities used.

\section{RESULTS}

In this article, two different electromagnetic harvester structures were investigated both numerically and experimentally. The harvester models were validated by comparing between the numerical and pre-test results. Then in the field tests, the power card designed with the harvester placed on the transformer line was fed. This card was taken with RF via sensor interface designed with data acquisition system.

In the preliminary experiments of energy harvesting from the electromagnetic field made with the core type core model introduced in the literature, it was observed that it harvested less energy than the double $\mathrm{C}$ model due to the single C core air gap. Despite these qualities, these disadvantages provide high flow saturation and ease of assembly. Core type models offer a great advantage especially in terms of their use in transmission lines with high current. Iron loss calculated using analytical equations of both $\mathrm{C}$ models is very close to iron loss value calculated with Ansys Maxwell. The voltage measurement induced in the windings of both models and the result of Ansys Maxwell are compatible with each other.

In the prototype energy harvester system, where the field was tested, energy was harvested from the electromagnetic field. The battery is charged with this energy. Data were successfully obtained from air temperature, air pollution and thermocouple via power control card. These data can be received and recorded in real time on the designed interface. It has been observed that there is a maximum of $3.11 \%$ in air temperature measurement and $5.73 \%$ in transformer temperature measurement. This difference is expected to decrease as the sensitivity of the sensors we use increases. Considering the Performance / Cost, it was seen that the system designed could be used to obtain data from the transmission lines. The general advantages of the designed prototype are listed below:

- It is capable of receiving data as long as there is energy instead of sensor systems used in current power lines and affected by adverse environmental conditions.

- Environmental data around the line where this system is used can be shared with relevant places without interruption.

- As it is known, monitoring the temperature change is essential for the life determination of the transformer. Transformer manufacturers can record the sensor data of the transformer during the warranty period.

- Transformer temperature rise test (IEC ISO / EN 60076-2) can be performed more cost-effectively than a datalogger.

\section{ACKNOWLEDGMENT}

The authors would like to thank the MEKSAN Company for their laboratory testing processes. Ansys Maxwell software used in this study was provided by Harran University Scientific Research Project Unit (Project No: 18060).

\section{CONFLICTS OF INTEREST}

No conflict of interest was declared by the authors.

\section{REFERENCES}

[1] Judd, M., Zhu, M., and Roscoe, N., "Powering Sensors Through Energy Harvesting", Euro TechCon. Glasgow, Scotland, 1-9, (2012). 
[2] De Moraes Júnior, T. O., Rodriguez, Y. P. M., de Sousa Melo, E. C., dos Santos, M. P., and de Souza, C. P., "Energy harvesting based on magnetic dispersion for three-phase power system", Energy and Power Engineering, 5(3): 20-23, (2013).

[3] Zhao, X., Keutel, T., Baldauf, M., and Kanoun, O., "Energy Harvesting for Overhead Power Line Monitoring. Systems", Signals and Devices (SSD), International Multi-Conference, (9): $1-5,(2012)$.

[4] Bayindir, R., Irmak, E., Colak, I., and Bektas, A., "Development of a real time energy monitoring platform", International Journal of Electrical Power \& Energy Systems, 33(1): 137146, (2011).

[5] Irmak, E., Calpbinici, A., and Guler, N., "Design of an energy monitoring system for a mediumscale plant", Pamukkale University Journal of Engineering Sciences, 18(2): 123-131, (2012).

[6] Irmak E., Göçmen G., Köse A., "A Smart Home Application Based on Wireless Sensor Networks", V. European Conference on Renewable Energy Systems (ECRES'2017), Sarajevo, Bosnia-Herzegovina, 1-5, (2017).

[7] Yaman, O., Biçen, Y., "An Internet of Things (IoT) based Monitoring System for Oil-immersed Transformers", Balkan Journal of Electrical and Computer Engineering, 7(3): 226-234, (2019).

[8] Yang, F., Du, L., Wang, D., Wang, C., Wang, Y., "A novel self-powered lightning current measurement system”, IEEE Transactions on Industrial Electronics, 65(3): 2745-2754, (2017).

[9] Wang, W., Huang, X., Tan, L., Guo, J., and Liu, H., "Optimization Design of An Inductive Energy Harvesting Device for Wireless Power Supply System Overhead High-Voltage Power Lines", Energies, 9(4): 242, 2016.

[10] Liu, Y., Xıe, X., Hu, Y., Q1an, Y., Sheng, G., J1ang, X., and Liu, Y., “A Novel High-Density Power Energy Harvesting Methodology For Transmission Line Online Monitoring Devices", Review of Scientific Instruments, 87(7): 075119, (2016).

[11] Maharjan, P., Salauddın, M., Cho, H., And Park, J. Y., “An Indoor Power Line Based Magnetic Field Energy Harvester For Self-Powered Wireless Sensors In Smart Home Applications", Applied Energy, 232: 398-408, (2018).

[12] Boles, J. D., Ozpınec1, B., Tolbert, L. M., Burress, T. A., Ayers, C. W., And Baxter, J. A., "Inductive Power Harvesting For a Touchless Transmission Line Inspection System", IEEE, Power and Energy Society General Meeting, Boston, MA, USA, 1-5, (2016).

[13] Yang, F., Du, L., Wang, D., Wang, C., And Wang, Y., “A Novel Self-Powered Lightning Current Measurement System”, IEEE Transactions on Industrial Electronics, 65(3): 2745-2754, (2018).

[14] Wu, Z., Nguyen, D. S., White, R. M., Wright, P. K., O’Toole, G., and Stetter, J. R., "Electromagnetic energy harvester for atmospheric sensors on overhead power distribution lines”, In Journal of Physics: Conference Series , IOP Publishing, 1052(1): 012081, (2018)

[15] Dos Santos, M.P., Vieira, D.A., Rodriguez, Y.P.M., De Souza, C.P., De Moraes, T.O.,Freire, R.C.S., "Energy harvesting using magnetic induction considering different core materials", IEEE International Instrumentation and Measurement Technology Conference (I2MTC), Montevideo, Uruguay, (2014) 
[16] Sordiashie, E., Moayedi, S., Alahmad, A., Polese, L., Alahmad, M., "Harvesting from Ambient Energy: Designing Enabling Technologies for Sustainable Buildings", IEEE International Conference on Electro Information Technology (EIT), Brookings, SD, USA, 069-078, (2019).

[17] Wang, Z., Du, J., Wang, R., Huang, W., Hu, W., Wu, J., and HE, X., “An Enhanced Energy Harvesting Method Based On Resonant Current Transformer For High Voltage AC Cable Monitoring Equipment", IEEE Applied Power Electronics Conference and Exposition, (APEC 2014), Fort Worth, TX, USA, 3455-3459, (2014).

[18] White, R. M., Nguyen, D. S., Wu, Z., And Wright, P. K., “Atmospheric Sensors and Energy Harvesters on Overhead Power Lines", Sensors, 18(1): 114-114, (2018).

[19] Paul, S., Bashır, S., And Chang, J., "Design of a Novel Electromagnetic Energy Harvester with Dual Core for Deicing Device of Transmission Lines", IEEE Transactions on Magnetics, 55(2): $1-4,(2018)$.

[20] Yuan, S., Huang, Y., Zhou, J., Xu, Q., Song, C., And Thompson, P., "Magnetic Field Energy Harvesting Under Overhead Power Lines", IEEE Transactions On Power Electronics, 30(11): 6191-6202, (2015).

[21] Zhuang, Y., Xu, C., Yuan, S., He, C., Chen, A., Lee, W. W., And Huang, Y., “An Improved Energy Harvesting System On Power Transmission Lines", IEEE Wireless Power Transfer Conference, Taipei, Taiwan, 1-3, (2017).

[22] Kabakulak, M., Arslan, S., "Numerical analysis of the harvester having toroidal structure and examination of the application results", International Advanced Researches and Engineering Journal (IAREJ), (2020).

[23] Kabakulak M., Gulluoglu, M. T., Arslan, S., "Comparison of energy harvesters according to change of conductor form", 1st International Akdeniz Symposium, Mersin, Turkey, 16-26, (2018).

[24] Kabakulak, M., Arslan, S., "Design and Application of an Electromagnetic Energy Harvester for Wireless Sensor Network", In 2020 International Conference on Electrical, Communication, and Computer Engineering (ICECCE), Istanbul, Turkey, 1-6, (2020).

[25] Yuan, S., Huang, Y., Zhou, J., Xu, Q., Song, C., and Yuan, G., “A High-Efficiency Helical Core For Magnetic Field Energy Harvesting”, IEEE Transactions on Power Electronics, 32(7): 53655376, (2017).

[26] Moon, S. R., Ohodnicki, P., Byerly, K., and Beddingfield, R., "Soft magnetic materials characterization for power electronics applications and advanced data sheets", IEEE Energy Conversion Congress and Exposition (ECCE), Baltimore, MD, USA, 6628-6633, (2019).

[27] National Energy Technology Laboratory. METGLAS $®$ 2605-SA1 core datasheet. Available: https://www.netl.doe.gov/sites/default/files/netlfile/METGLAS-2605-SA1-CoreDatasheet_approved\%5B1\%5D.pdf

[28] Fenercioğlu, A., Tarimer, I., "Solution Processes of a Magnetic System's Magnetostatic Analysis with Maxwell 3D Field Simulator", Selçuk Teknik Dergisi, 6(3): 221-240, (2007).

[29] Kabakulak M., "Energy harvesting from electromagnetic fields around overhead power lines", MSc Thesis, Harran University, Graduate School of Natural and Applied Sciences, Şanliurfa, (2020). 
[30] Rosca, S., Riurean, S., Leba, M., and Ionica, A., "A Reliable Wireless Communication System for Hazardous Environments", In The 2018 International Conference on Digital Science, Springer, Cham, 235-242, (2018).

\section{APPENDIX}

The power and charge circuit diagram of the designed circuit is as follows.

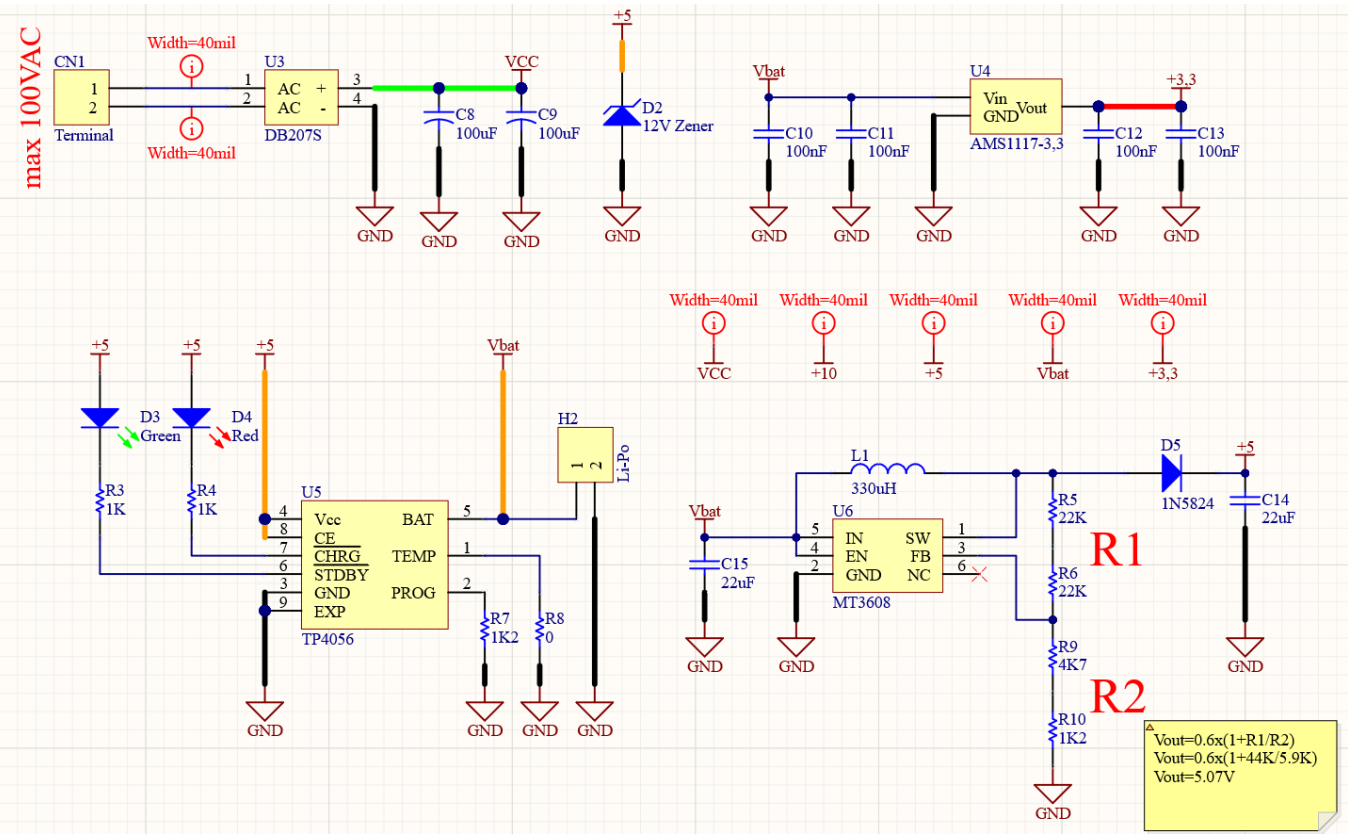

The microprocessor circuit schematic of the designed circuit is as follows.

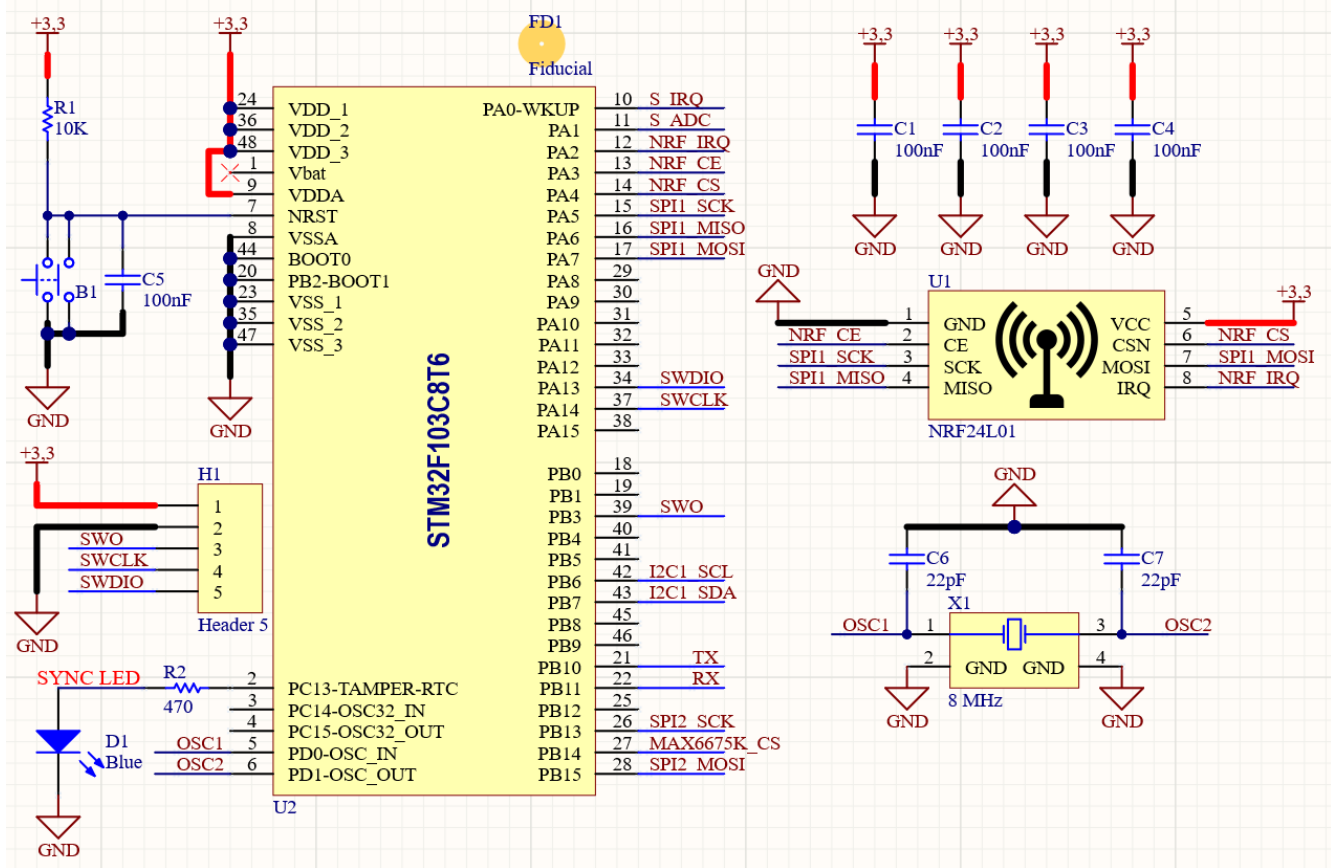


Sensor circuits schematics of the designed circuit are as follows.

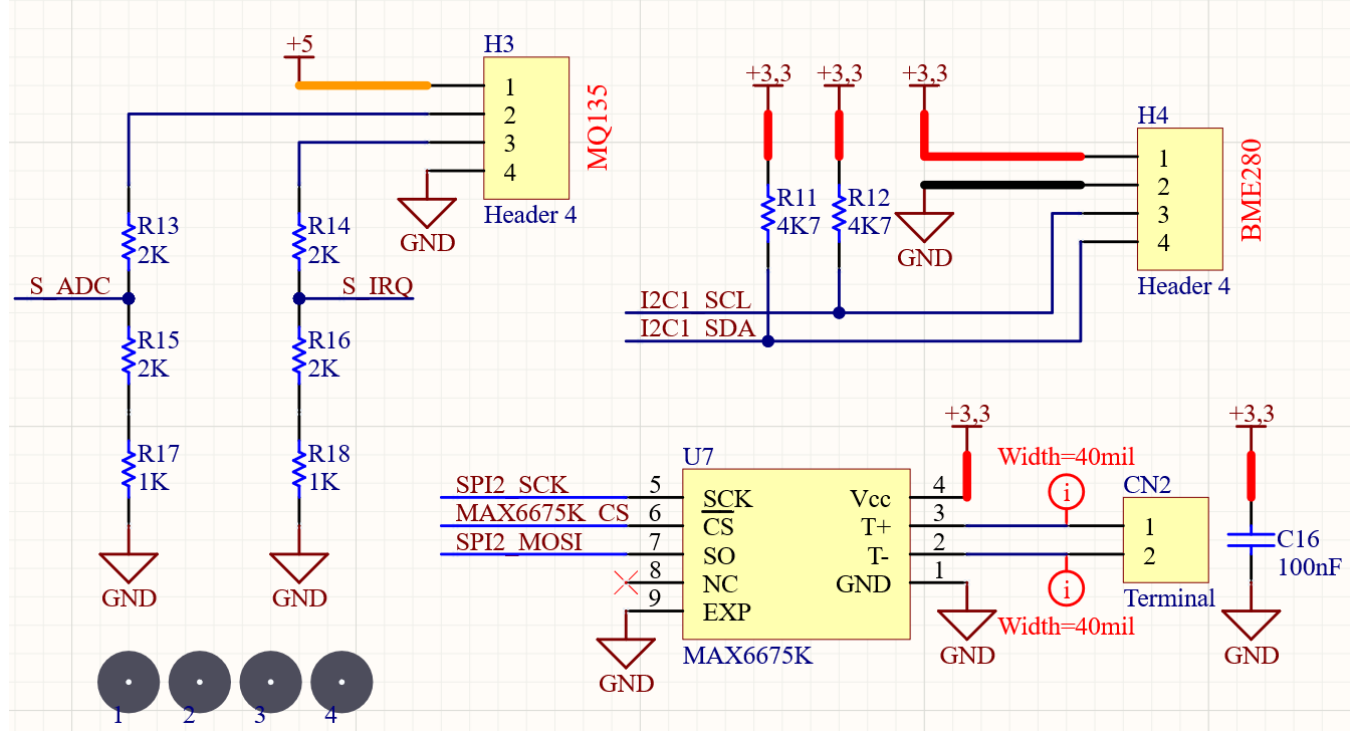

The serial port converter circuit diagram for the designed receiver circuit is as follows.

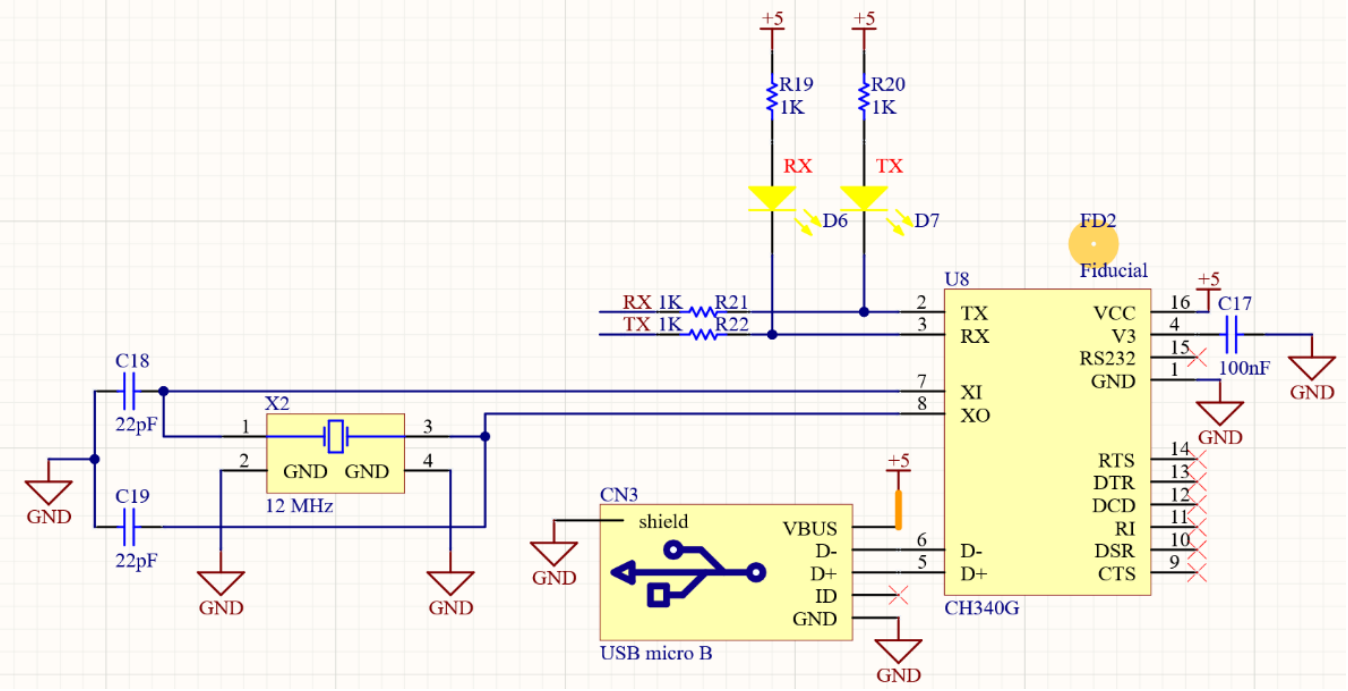

